\title{
Práticas de trabalho e as dimensões tácitas e estéticas DA APRENDIZAGEM DE OPERADORES DE ROCHAS ORNAMENTAIS
}

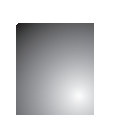

\author{
Practical work and the tacit and aesthetic dimensions of \\ learning operators ornamental rocks
}

Kátia Cyrlene de Araujo Vasconcelos
Doutoranda em Administração. Universidade Federal do Espirito Santo - UFES. Fucape Business School. Vitória, ES. Brasil.
E-mail: katia.vasconcelos@oi.com.br

\section{Claudia Xavier Cavalcanti}

Doutoranda em Administração. Universidade Federal do Espirito Santo - UFES. Vitória, ES. Brasil.

E-mail: claudiaxc.andrade@terra.com.br

\section{Annor da Silva Junior}

Professor do Programa de Pós-graduação em Administração (PPGAdm) e do Programa de Pós-graduação em Ciências Contábeis (PPGCon) - UFES. Universidade Federal do Espirito Santo - UFES. Vitória, ES. Brasil. E-mail: annorsj@gmail.com

\section{Resumo}

O objetivo desse artigo é compreender como as práticas de trabalho possibilitam o processo de aprendizagem dos operadores do ramo de rochas ornamentais, utilizando uma lente teórica que entende que esse processo ocorre a partir de uma teia de relações sociais e culturais que são institucionalizadas e estabelecidas e sustentadas por um grupo (GHERARDI, 2001, 2006). Assim, desenvolveu-se uma pesquisa de caráter qualitativa em uma indústria de rochas ornamentais. A coleta foi realizada por meio de entrevistas e observações assistemáticas. A análise dos dados demonstra que o processo de aprendizagem dos operadores da empresa Jazida se sustenta em uma construção social, por meio de práticas de socialização, de segurança e do senso estético, nas quais a colaboração, a interação, o desejo de compartilhar, a vontade de aprender, a ativação da percepção e de sentimentos, são fontes importantes para a geração, a disseminação e o compartilhamento do conhecimento e o aprendizado.

Palavras chaves: Aprendizagem; Práticas de Trabalho; Práticas de Socialização; Senso estético; Aprendizagem de Grupos.

\section{Abstract}

The purpose of this paper is to understand how work practices enable the learning of individuals in workspaces using a theoretical approach that believes that this process occurs from social and cultural relations that are institutionalized, established and supported by a group (GHERARDI; 2001, 2006). In order to develop this, a qualitative research study was conducted in one manufacturer of polished granite slabs. The data was collected through interviews and unsystematic observations. This study concluded that the learning process of the researched company is based on a social construction, through socialization practices, safety and aesthetic sense, where collaboration, interaction, the desire to share, and to learn, the activation of perception and feelings are important sources for generation, dissemination and sharing of knowledge and learning.

Key words: learning, work practices, socialization practices, aesthetic sense, learning groups. 


\section{INTRODUÇÃO}

As abordagens tradicionais de aprendizagem organizacional definem o conhecimento organizacional como informações de alto valor agregado (DAVENPORT; DE LONG; BEERS, 1998); um ativo invisivel e uma forma de capital intelectual que pode ser quantificada, estimada e trocada como uma mercadoria de alto valor (STEWART, 1994); e como um conjunto composto por domínio pessoal, modelos mentais, visão compartilhada, aprendizado em equipe e pensamento sistêmico (SENGE, 2010). Para esses autores, é possível estabelecer medidas de conhecimento intelectual para determinar seu valor de mercado e sua contribuição para a rentabilidade da empresa (NICOLINI, GHERARDI; YANOW, 2003).

No entanto, alternativas à abordagem funcionalista têm surgido para se contrapor a esta ideia de aprendizagem cognitivista, que considera que a aprendizagem só acontece na mente das pessoas e é considerada como um capital intelectual. Nesse sentido, os conceitos de prática e atividade têm atraído atenção de acadêmicos e profissionais que trabalham com aprendizagem no contexto organizacional. Ambos têm procurado explorar a noção de que o conhecimento e a aprendizagem são fenômenos essencialmente sociais e culturais.

O conhecimento em ação está situado no contexto histórico, social e cultural em que ele surge e é incorporado em uma variedade de formas e meios de comunicação (NICOLINI, GHERARDI; YANOW, 2003; GHERARDI, 2001, 2006). Uma dessas abordagens refere-se à visão sociológica da aprendizagem nas organizações (GHERARDI; NICOLINI; ODELLA, 1998; GHERARDI; NICOLINI, 2000; BISPO; MELLO, 2012; HAGER, 2012), na qual o ambiente social é o espaço onde ocorrem os processos de aprendizagem e a geração do conhecimento.

Dentre os diversos ambientes sociais existentes, temos os ambientes de trabalho e, especificamente, a indústria do ramo de rochas ornamentais. Esse setor é reconhecido por formar sua própria mão-de-obra, havendo poucos profissionais com formação técnica específica que atendam às necessidades do segmento. Os processos desenvolvidos em marmorarias exigem um grau de qualificação muito específico. Portanto, entender como as práticas de trabalho favorecem a aprendizagem e de que forma isso ocorre nesse setor é uma oportunidade de estabelecer uma clara ligação entre os dados coletados e a teoria, contribuindo para a ampliação dos estudos existentes.

Além disso, o fato de realizar uma pesquisa empírica com foco na aprendizagem nos espaços de trabalho baseado nos estudos da prática (ANTONELLO; GODOY, 2010; GHERARDI, 2006; NICOLINI; GHERARDI; YANOW, 2003; BISPO; GODOY, 2012; BISPO, 2013), permite ampliar as pesquisas sobre conhecimento e aprendizagem na perspectiva dos estudos baseados em práticas, contribuindo para uma melhor compreensão em relação a como as pessoas aprendem umas com as outras em seu cotidiano.

Segundo Bispo (2013a, 2013b), há estudos que apresentam uma possibilidade de aprendizagem nos espaços de trabalho ao utilizar os conceitos de participação periférica legitimada, comunidades de prática e currículo situado, para buscar entender os padrões das atividades de instrução para os novatos que ingressam nas organizações (GHERARDI; NICOLINI; ODELLA, 1998; GHERARDI, 2001, 2006). Portanto, é exatamente nesta visão periférica de aprendizagem no setor de rochas ornamentais que se encontra a lacuna a ser explorada por esta pesquisa, ao basear o trabalho na prática da aprendizagem dos operadores de rochas, que representa a visão periférica de um processo formado por conceitos de segurança, socialização e estética, categorias não exploradas anteriormente de forma conjunta e neste setor em específico.

Diante disso, e considerando a importância econômica e social do setor, as baixas oportunidades de formação, a exigência de que as organizações e profissionais produzam seus próprios conhecimentos $e$, entendendo que o processo de aprendizagem se dá na prática, a partir de uma teia de relações sociais e culturais que são estabelecidas e sustentadas por um grupo e que são institucionalizadas (GHERARDI; 2001, 2006), pretende-se compreender como as práticas de trabalho possibilitam o processo de aprendizagem dos operadores do ramo de rochas ornamentais.

Para isso, estruturou-se o artigo em quatro partes além da presente introdução. Na primeira, apresenta-se o referencial teórico, na segunda, os aspectos metodológicos e na sequência, a apresentação dos dados, discussão $e$ as considerações finais. 


\section{Referencial Teórico}

\subsection{A aprendizagem nos espaços de trabalho e a prática situada.}

A aprendizagem organizacional tem sido abordada por diferentes vertentes ao longo do tempo. $\mathrm{O}$ tema, que tem sido discutido em diferentes áreas do conhecimento, apresenta multiplicidade de enfoques e conceitos, além de sobreposições (ANTONELLO; GODOY, 2010). Há estudos que tratam o conhecimento e a aprendizagem organizacional de modo objetivo, prático, prescritivo e gerencial, ou seja, como um ativo e um capital pertencente à organização (STEWART, 1994; NONAKA; TAKEUCHI, 1997; DAVENPORT; DE LONG; BEERS, 1998; KUNIYOSHI, 2008; SENGE, 2010). Nessa visão técnica, aprendizagem organizacional está relacionada ao processamento eficaz de informações, interpretação, resposta a informações tanto de dentro da organização quanto de fora. Como o foco central está nos dados, nas suas fontes e na forma como são transformados para gerar mudanças, não se leva em consideração o significado que este dado tem para os indivíduos, além de se entender que a aprendizagem se dá na mente das pessoas. Nessa visão, encontram-se as abordagens associadas a uma epistemologia positivista com modelos normativos/ prescritivos (EASTERBY-SMITH; ARAUJO, 2001; PRANGE, 2001).

Por sua vez, na visão social, a aprendizagem organizacional está relacionada à maneira como as pessoas atribuem significados às suas experiências de trabalho, que podem derivar de fontes explícitas ou tácitas, sendo entendida como um processo socialmente construído. Nessa perspectiva, a aprendizagem é o resultado das interações sociais e está entrelaçada na cultura de uma organização, estando associada a abordagens de uma epistemologia interpretativa em que se busca descrever processos e resultados de aprendizagem (EASTERBY-SMITH; ARAUJO, 2001; PRANGE, 2001).

Os conceitos de prática e atividade têm atraído atenção de acadêmicos e profissionais que trabalham com a aprendizagem no contexto organizacional. Ambos têm procurado explorar a noção de que o conhecimento e a aprendizagem são fenômenos essencialmente sociais e culturais. Isso implica dizer que o conhecimento organizacional e a aprendizagem não podem ser concebidos como processos mentais que residem nas cabeças dos indivíduos. O conhecimento em ação é situado em um contexto histórico, social $e$ cultural em que ele surge e é incorporado em uma variedade de formas e meios de comunicação (NICOLINI, GHERARDI; YANOW, 2003; GHERARDI, 2001, 2006).

Pensar no aprendizado por meio da participação na prática permite um foco nas ações do dia a dia, onde o aprendizado se configura no fluxo da experiência, com ou sem conhecimento específico da atividade. $\mathrm{Na}$ vida organizacional diária, o trabalho, o aprendizado, a inovação, a comunicação, os conflitos, as metas, suas interpretações e história, estão todos presentes na prática, ou seja, são parte da existência humana (GHERARDI, 2001, 2006).

Uma abordagem baseada na prática oferece, desse modo, uma alternativa aos estudos sobre o conhecimento $e$ aprendizagem nas organizações, apresentando uma nova ontologia e epistemologia. A ontologia prevista por uma abordagem da prática é baseada em um vocabulário que é relacional, construtivo, heterogêneo e situado. Nessa perspectiva, o mundo parece ser relacionalmente constituído por uma rede de elementos heterogêneos e perpetuados por processos em série, que fazem sentido e que incluem as práticas discursivas (NICOLINI, GHERARDI; YANOW, 2003). Bispo e Godoy (2012) afirmam que a aprendizagem organizacional é o que constitui a própria organização, sendo estas, o resultado de seus processos de aprendizagem e práticas cotidianas.

Bispo (2013b), ao fazer uma revisão da contribuição dos estudos de Gherardi sobre a prática, aponta que a autora define uma prática como um modo relativamente estável no tempo e socialmente reconhecido de ordenar elementos heterogêneos em um conjunto coerente.

Partindo dessa definição, Gherardi (2006) faz referência a quatro características fundamentais para o entendimento do termo prática. Primeiro, como um grupo de atividades que adquire significado e torna-se reconhecido enquanto unidade, de modo que o foco deve sempre ser no conjunto que as atividades assumem em um contexto de ação situada. Segundo, o tempo em que essa ação situada se mantém. Terceiro, a condição de ser reconhecida socialmente e, por fim, um modo de organização de mundo. 
Sendo assim, Bispo (2013a) argumenta que ao se adotar essas características para o entendimento da prática, Gherardi $(2006 ; 2012)$ evidencia seu alinhamento teórico às premissas etnometodológicas de Garfinkel (2006), além do pressuposto fenomenológico de que a realidade não existe a priori, mas ela é aquilo que as pessoas vivem e conhecem. Logo, uma prática é algo que dá identidade a um grupo que se organiza a partir dela, sua aprendizagem ocorre por meio das interações entre os atores sociais e os elementos humanos e não humanos, e é resultado de uma dimensão tácita e estética dessas interações (GHERARDI, 2006).

A abordagem também enfatiza que o processo de se tornar um membro em uma comunidade de prática é uma fonte crucial de aprendizagem para os novatos e a comunidade. Lave e Wenger (1991) argumentam que essa participação vai se dando de forma gradual, inicialmente naquilo que se denomina participação periférica legitimada, até que se aumente o nível de engajamento para a participação plena. O termo "periférico" denota a existência de um caminho que um novo membro deve seguir para ser reconhecido como participante da comunidade. Ao mesmo tempo, a ideia relacionada de "legítimo" está em conexão com a institucionalização (GHERARDI; NICOLINI; ODELLA,1998). Ou seja, novos membros da comunidade são socializados para suas práticas e conhecimentos distintos, e adquirem um volume de conhecimento que eles deixam como um legado, com algumas modificações, aos seus sucessores. Dessa forma, perpetuam não só a comunidade, mas também o seu volume de conhecimento prático.

Sair da condição de um participante periférico para um participante legítimo implica ter a capacidade de identificar aspectos que são importantes nesse contexto. Para isso, torna-se fundamental identificar quem são as pessoas, o que fazem no dia a dia, como são estabelecidas as conversas, a rotina, as relações entre os membros e os não membros da comunidade e o que precisa ser aprendido para se tornar um membro legítimo, em um processo onde entendimento e experiência estão em interação, sendo mutuamente constitutivos (GUDOLLE; ANTONELLO; FLACK, 2012).

Gudolle, Antonello e Flach (2012) argumentam que participação periférica legitimada é mais do que um processo de aprendizagem por parte dos novatos. Para os autores, "é uma relação recíproca entre pessoas e prática. Isso significa que, quando os aprendizes se movem para a participação plena, a comunidade de prática não está em um contexto estático, a prática em si está em movimento" (GUDOLLE; ANTONELLO; FLACK, 2012, p.25). Neste sentido, os autores defendem que todos podem ser considerados novatos quando se pensa em futuro de uma comunidade em constante mudança

Desde que o conhecimento é integrado e distribuído na vida da comunidade, o aprender é um ato de pertencimento, no qual a aprendizagem requer necessariamente envolvimento. A aprendizagem não pode ter lugar se a participação não é possível: o desenvolvimento profissional dos membros e o desenvolvimento da prática sustentada pela comunidade andam de mãos dadas, ou seja, a sua identidade e a da comunidade evoluem em paralelo (NICOLI, GHERADI; YANOW, 2003; GHERARDI; STRATI, 2014).

Gherardi e Nicolini (2000) ressaltam a noção de que uma comunidade de prática foca em aspectos importantes do conhecimento organizacional, $e$ especialmente grande parte dele que é tácito e não formalizado, e que este conhecimento pode ser perpetuado e modificado para dar origem à aprendizagem. A própria comunidade perpetua modos de saber que não exigem uma explicação formal. Novos membros da comunidade são socializados para suas práticas e conhecimentos distintos, e adquirem um volume de conhecimento que eles deixam como um legado, com algumas modificações, aos seus sucessores. Dessa forma, perpetuam não só a comunidade, mas também o seu volume de conhecimento prático. Comunidades de prática constituem uma teia de relações que vão além dos limites das organizações individuais, proporcionando um canal para mudanças no volume de conhecimento organizacional.

A ideia, portanto, que surgiu para entender o fenômeno da aprendizagem organizacional, ressalta que é necessário examinar não só os mecanismos pelos quais o conhecimento é gerado ou assimilado dentro de uma comunidade, mas também aqueles em que esse conhecimento é traduzido através da rede invisível de contatos entre diferentes comunidades de prática (GHERARDI; NICOLINI, 2000; GHERARDI; 2001, 2006).

Ao se adotar neste estudo a lente da prática, busca-se concentrar na aprendizagem como uma prática situada, afastando cada vez mais das características 
de passividade e determinismo, assim como da visão cognitiva presente nas abordagens mais tradicionais, compreendendo que o conhecimento se faz de forma contínua e provisória (GHERARDI, 2001, 2009; GHERARDI; PERROTTA, 2014).

Gherardi e Perrota (2014, p.136) enfatizam que o contexto não é "recipiente para ação, mas uma situação em que os interesses dos atores $e$ as oportunidades proporcionadas pelo ambiente se encontram e são reciprocamente definidos". Ao se concentrar na análise do conhecimento dentro de uma prática situada é possível compreender onde o conhecimento é construído socialmente. O knowing não pode ser separado do doing, porque é constituído a partir das práticas situadas onde o conhecimento é produzido e reproduzido. Assim, compreende-se que a aprendizagem é uma composição de knowing e doing (GHERARDI, 2001, 2009; BISPO, 2013a) e com este olhar propõe-se discutir na sequencia as práticas de segurança e de senso estético.

\subsection{A prática da Segurança}

Questões de segurança e confiabilidade em organizações têm se se tornado centro de interesse, não só por causa de sua importância, mas também por causa da ênfase crescente colocada na tomada de decisão das empresas responsáveis por proteger a saúde dos trabalhadores e do meio ambiente. Por um lado, o debate científico salienta que temos uma sociedade de risco (BECK, 1992), por outro lado, que o ser humano e os fatores organizacionais estão na origem das catástrofes industriais (TURNER; PIDGEON, 1997).

As abordagens tradicionais de segurança, no que diz respeito tanto aos desastres como em acidentes de trabalho industriais, consideram a segurança como uma propriedade que se objetiva de tecnologias $e$ artefatos seguros. Isso é chamado de rota técnica para a segurança e suportado por via normativa que vê a segurança como o resultado da aplicação de regras e regulamentos que prescrevem comportamentos individuais e coletivos seguros (GHERARDI; NICOLINI, 2000; GHERARDI; STRATI, 2014). No entanto, há um movimento que sai do contexto do risco e passa a ver a segurança como um movimento cultural em curso, ou seja, sai de um foco da segurança como um fator objetivo inerente às condições de risco, para a produção social das condições de segurança sustentada por uma cultura de segurança (GHERARDI; NICOLINI; ODELLA, 1998; GHERARDI; STRATI, 2014).

O que Gherardi e Nicolini (2000) chamam de segurança é o resultado de um conjunto de práticas moldadas por um sistema de símbolos e significados que orientam a ação, mas que consistem em algo mais. Segurança, por conseguinte, pode ser vista como uma prática situada, uma propriedade emergente de um sistema sociotécnico, o resultado final de um processo coletivo de construção, um "fazer" que envolve pessoas, tecnologias e formas textuais e simbólicas montadas dentro de um sistema de relações materiais.

Quando se reconhece que o conhecimento não é fruto da mente, mas de uma construção simbólica coletiva que se dá na interação e no entrelaçamento de ambiente, linguagem, mundo social e material, é possível compreender o lugar das emoções, dos afetos, do conhecimento sensível, da paixão e do desejo pelo fazer e aprender, questões que serão discutidas na sequência.

\subsection{A dimensão estética}

A partir do trabalho de Reckwitz (2002), observa-se uma valorização do conhecimento sensível e estético, do corpo, dos movimentos, das rotinas e práticas na pesquisa organizacional. Para o autor, a prática se apresenta em primeiro lugar como atividades corporais regulares, considerando que uma prática social é uma atividade física regular que se mantém unida por formas socialmente padronizadas de entendimento e knowing.

Gherardi $(2000,2006)$ argumenta que o conhecimento é algo que não está na mente das pessoas, mas é uma construção coletiva, produzida, reproduzida e modificada por meio das práticas. Ao considerar o conhecimento como situado, Gherardi $(2009,2014)$ argumenta que este processo de saber está situado no corpo, na dinâmica das interações, na linguagem e no contexto físico. Isso significa dizer que o conhecimento é adquirido por meio dos sentidos, logo, (i) é estético e não mental; (ii) as interações acontecem entre elementos humanos e não humanos, já que utiliza de todos os recursos disponíveis; (iii) as práticas discursivas produzem ações; e (iv) o espaço é dotado de significados e influencia na institucionalização das práticas.

Strati $(2007,2014 c)$ define estética como uma forma de conhecimento humano fornecida pelos 
órgãos dos sentidos e pela capacidade que temos de fazer um juízo estético. Trata-se de um sentimento que é individual e coletivamente construído pelos indivíduos nas ações interativas de viver as experiências, compreender e julgar através de sentidos e gostos (STRATI, 2003, 2014d; GHERARDI; STRATI, 2014). Diz respeito à nossa corporeidade refinada no ambiente organizacional, o que implica dizer que a abordagem estética rompe com a tradicional dicotomia mente/corpo e põe em evidência o corpo como artífice do conhecimento (BERTOLINI; CAPPELLI; BRITO, 2014). A estética não trata somente de uma bonita organização, de uma atividade interessante, de uma prestação de um serviço de alto nível, mas também dos maus cheiros no local de trabalho, do barulho e das ocorrências desagradáveis.

Strati (2007) argumenta ainda, que os processos envolvidos na criação de um artefato dizem respeito, não às suas propriedades ontológicas, mas às suas características estéticas. Nas organizações, cadeiras podem, por exemplo, revelar status, excluir alguém que chegou atrasado a uma reunião, logo, não é somente um artefato material, mas imaterial também. Ainda para o autor, a estética é o motor da organização e a informação que a estética dá, se baseia em processos contínuos de construção, desconstrução e reconstrução simbólica, privilegiando a compreensão empática, ao invés da compreensão causal.

Também há conexão estreita entre estética $e$ conhecimento tácito, pois as pessoas adquirem o conhecimento tácito da vida organizacional pela ativação de sua percepção e do conhecimento não intelectual. Nesse sentido, Strati (2007, 2014a, 2014b) defende que a partir de uma perspectiva estética, o conhecimento tácito é uma forma diferente e específica, que permite por meio de tentativas e organização, que as práticas organizacionais sejam inventadas, realizadas, aprendidas e ensinadas pelos participantes na construção social da vida organizacional.

Gherardi e Rodeschini (2016) argumentam que o saber-em-prática às vezes é mobilizado na prática discursiva, especialmente quando é abertamente discutido e contestado. Entretanto, de forma mais frequente é pré-verbal, tácito e pessoal. Logo, grande parte dessa maneira de conhecer é sensorial e está compreendida nos juízos estéticos que sustentam "a maneira correta de praticar".
Nesse contexto de estética, há uma discussão sobre o corpo, como algo munido de todo o potencial de mobilização de conhecimento sensível e de gosto, como um novo elemento de análise. O fazer pelo gosto (taste-making) é apresentado por Gherardi (2009) como um elemento que influencia na sofisticação das práticas, pois mobiliza conhecimento sensível, como a habilidade corporal para perceber e gostar, além de compartilhar um vocabulário que permite a comunicação de experiências sensíveis, influenciando no engajamento ao objeto da prática.

$\mathrm{Na}$ busca contínua por refinamento das práticas, pode-se dizer que os atores praticantes são então movidos pela mesma lógica que um artista busca na perfeição de sua obra (BERTOLINI; CAPPELLI; BRITO, 2014). Portanto, o julgamento estético dos praticantes não somente sustenta as práticas socialmente, mas contribui também para o engajamento no que eles fazem e para a dinâmica da mudança nas práticas, além dos impactos na subjetividade, onde o compartilhamento do prazer de fazer é também o compartilhamento do prazer de ser (GHERARDI, 2009).

Com base na revisão da literatura realizada, pode-se depreender que a aprendizagem à luz dos estudos baseados em prática remete à natureza coletiva, situada, relacional e provisória do conhecimento. Conhecer não é fruto da mente, mas de uma construção simbólica coletiva que se dá na interação e na negociação em um entrelaçamento de ambiente, linguagem, mundo social e material, reconhecendo o lugar das emoções, dos afetos, da estética. Conhecimento, portanto, é uma realização social contínua, constituída e reconstituída nas práticas e, ao se estudar as práticas de trabalho, o que se faz é estudar o conhecimento em sua elaboração (GHERARDI, 2016).

\section{Metodologia}

Buscando compreender como as práticas de trabalho possibilitam a aprendizagem dos indivíduos nos espaços de trabalho optamos pela condução de uma pesquisa qualitativa. A justificativa para esta escolha é que esta abordagem permite a compreensão aprofundada do fenômeno no contexto em que ocorre, revelando o ponto de vista $e$ o entendimento das pessoas envolvidas, a partir da interação com o fenômeno 
em estudo, permitindo a observação, exploração $e$ compreensão sob uma perspectiva cultural-interpretativista de aspectos relacionados às práticas de um grupo (BOGDAN; BIKLEN, 1994; BANSAL; CORLEY, 2011).

Como lócus da pesquisa foi escolhida uma empresa do setor de rochas ornamentais localizada no município de Serra, no estado do Espírito Santo. A empresa é de base familiar e atua no setor desde 1989, estando entre as 10 maiores do ramo no Espírito Santo. É parte de uma das 6 unidades de negócios que compõem o Grupo empresarial, tendo o presente estudo focado na sua matriz, onde atuam 86 empregados. Para preservar a identidade do grupo empresarial, neste estudo, adotaremos a denominação de Empresa Jazida.

A escolha do caso em estudo justifica-se pelo fato de que o Brasil figura entre os cinco maiores produtores de rochas ornamentais, sendo o Espírito Santo o principal produtor e o maior processador e exportador de rochas ornamentais do Brasil. O setor gera cerca de 110 mil empregos diretos em aproximadamente 10 mil empresas e é reconhecido como um formador de sua própria mão de obra (ABIROCHA, 2012). Este cenário é desafiador exigindo que as empresas desenvolvam cada vez mais estratégias de formação interna.

Sendo assim, por estarmos interessados em compreender como as práticas de trabalho possibilitam a aprendizagem dos indivíduos das dimensões técnicas e estéticas nos espaços de trabalho, entendemos que explorar as possibilidades deste setor e, em especial, da empresa Jazida seria uma grande oportunidade de estabelecer uma clara ligação entre os dados coletados e teoria sobre o tema, de forma a contribuir para a ampliação dos estudos existentes.

Para a coleta de dados utilizamos entrevistas semiestruturadas e observação não participante (KING, 1997; CRESWELL, 2010). Esta opção deve-se ao fato de o estudo considerar a perspectiva dos entrevistados como um dos elementos-chave de forma a possibilitar a compreensão e interpretação do fenômeno a partir da experiência que acumulam no ambiente pesquisado (ROSEN, 1991; DUNDON; RYAN, 2010). Os roteiros foram estruturados a partir de 3 elementos conceituais oriundos da teoria - processo de aprendizagem, as práticas de trabalho e a estética.

Inicialmente realizamos visita às dependências da empresa, acompanhadas por um dos diretores, de forma a conhecer todo o processo de produção e aprender sobre o vocabulário básico da área. Esse procedimento permitiu ampliar nosso conhecimento sobre o trabalho desenvolvido, facilitando a interação durante as entrevistas (ROSEN, 1991). A definição dos entrevistados da área operacional levou em consideração dois critérios: o tempo mínimo de 6 meses na empresa e atuação em diferentes processos produtivos. Com a observação destes critérios, foi possível ter o acesso aos profissionais que já conheciam o cotidiano da empresa, possuíam o conhecimento básico da operação e que já vivenciaram o processo de aprendizagem na organização.

Foram realizadas no total 10 entrevistas individuais abrangendo (1) diretor, (1) profissional da área comercial, (2) profissionais da área de $\mathrm{RH},(1)$ encarregado geral da produção, (1) encarregado de polimento e (4) operadores de produção. As entrevistas foram encerradas no momento em que percebemos que os entrevistados começavam a trazer os mesmos elementos.

Para as entrevistas foram utilizados dois roteiros semiestruturados. Para os profissionais que atuavam na linha de produção o roteiro tinha como objetivo explorar as práticas operacionais e o processo de aprendizagem do grupo no dia a dia. Por sua vez, o roteiro utilizado para os demais profissionais buscou explorar os processos organizacionais sob a responsabilidade de cada uma das áreas representadas e a interface com a área operacional.

Com a autorização dos informantes, todas as entrevistas foram gravadas, possibilitando transcrição posterior. Para preservar a identidade dos entrevistados, na apresentação dos dados, todos foram identificados pelo cargo que ocupam seguido de numeração quando havia mais que um ocupante do cargo.

A técnica empregada para a análise e interpretação dos dados foi a análise temática (GIL FLORES, 1994). Os elementos conceituais do referencial teórico e que também orientaram o protocolo de entrevistas, possibilitaram, a partir das entrevistas, identificar os temas a serem investigados (RYAN; BERNARD, 2003). Antes de atribuir significado aos dados encontrados, todas as sentenças ou palavras isoladas que se relacionavam com a nossa questão de pesquisa foram sendo destacadas e agrupadas por semelhanças $e$ posteriormente reagrupados. A partir da análise das respostas referentes às práticas de trabalho, que representava o roteiro de entrevistas do primeiro bloco, foi 
possível identificar quais práticas contribuíam para o processo de aprendizagem, passando a ser codificadas desta forma.

Após as repetidas leituras, cortes e marcações dos fragmentos, identificamos como subtemas: práticas de segurança, práticas de socialização e a prática do desenvolvimento do senso estético. A apresentação dos dados feita na seção seguinte refletiu cada uma destas práticas em um sentido cronológico do processo de aprendizagem que ocorre dentro da empresa jazida.

\section{Apresentação dos Resultados}

Os entrevistados, ao contarem sobre o ingresso no setor de rochas, relatam que nenhum deles possuía experiência prévia no setor, sendo todos oriundos de diferentes setores econômicos, tais como metal-mecânico, construção civil, comércio varejista, agricultura. A maioria dos profissionais do nível operacional possui o ensino fundamental ou médio à exceção do operador de menor tempo de empresa que cursa engenharia e os que atuam nas áreas administrativas. Estas informações iniciais já nos instigavam a entender de que maneira estes profissionais aprenderam o ofício de trabalhar com rochas ornamentais se não havia experiência prévia no setor ou uma qualificação específica e, desde o início, foi possível identificar que a empresa Jazida possui práticas que promovem o aprendizado destes profissionais. Estas práticas foram sendo apresentadas nas entrevistas e desde o contato inicial com o diretor, foi possível identificar a existência das práticas, a partir de falas que reforçavam isso.

Os profissionais da empresa Jazida atuam no dia a dia por meio de um trabalho interativo e de colaboração, compartilham conhecimentos e aprendizados sobre os processos e, sustentado pela disposição em aprender, a atenção ao processo e o cuidado, é possível se tornar operador. A fala do operador1, que atua na empresa há 3,5 anos, reflete esta evolução "Praticamente eu vou dizer que eu comecei como ajudante (...) aprendi a serrar, sou serrador, hoje estou praticamente quase pronto".

Os dados apresentados a seguir, possibilitarão a compreensão sobre este aprender na prática, identificando elementos do dia a dia que contribuem para esta ação.

\section{1 "Carinho é cuidado com você e com o outro" - a prática da segurança}

Após a admissão de um novo profissional que atuará na área de produção, a Jazida fornece um treinamento de segurança onde são apresentadas todas as regras e processos da empresa. Segundo a profissional de $\mathrm{RH} 1$, este treinamento "é fundamental porque neste momento ele aprende o que pode e o que não pode na empresa" e destaca ainda que " não precisa ir para a área com experiência mas precisa conhecer estas regras". Além do treinamento de segurança, é ofertado pela empresa o treinamento de ponte rolante e normas específicas de cada setor.

Observamos que estes programas iniciais de treinamento são reconhecidos pelos empregados como importantes para o aprendizado. Entretanto, os operadores fazem questão de destacar que não é por meio do curso e das informações que eles aprendem, e sim da prática, fazendo valer na área operacional o que aprenderam. O "fazer valer o que aprendeu" se dá na prática, no cuidado, na disciplina e na atenção, palavras recorrentes nas diferentes entrevistas.

O cuidado, a atenção e a disciplina, requisitos apontados pelos entrevistados como essenciais para o desenvolvimento da prática de segurança, são transmitidos entre eles, num processo de participação ativa e do compartilhamento dos conhecimentos e experiências adquiridas por quem já está há mais tempo na empresa, como nos contou o entrevistado operador1 "Quando o cara chega eu digo faz assim, isso aqui é perigo, tenha muita atenção e cuidado".

É no dia a dia, nas interações, que eles vão percebendo que se não desenvolverem um trabalho dentro das normas de segurança requeridas, utilizando os EPI's fornecidos pela empresa e cuidando da própria segurança, dos colegas, dos equipamentos e insumos, esse aprendizado não se efetivará e o trabalho não será desenvolvido da forma como se espera. A expectativa de uma atuação responsável é identificada na fala do encarregado de produção, quando nos conta que sempre lembra aos operadores que "(..)até a hora de você ir embora isso aqui é sua responsabilidade, é responsabilidade de todo mundo."

O agir com segurança, cuidando de si e dos outros e com a participação de cada um dos operadores foi o tema que emergiu nas entrevistas, demonstrando que 
estas práticas são muito presentes no dia a dia. Foi possivel depreender, a partir da exposição dos entrevistados, que este tema, tão presente nas organizações como regras da segurança no trabalho, é parte de uma prática com significado para os operadores da empresa Jazida.

\section{2 "Se você não aprender com a gente, sozinho não aprende não" - a prática da socialização.}

Após participar dos treinamentos obrigatórios de segurança, o operador chega à sua área de trabalho e a partir daí se inicia um processo de treinamento para a função. Segundo a profissional de $\mathrm{RH} 2$, o que se ensina logo na chegada são as normas do setor e a importância do trabalho em equipe porque "ele precisa entender como funciona a área $e$ aprender logo que é importante trabalhar em equipe para não prejudicar o seu trabalho e o dos outros".

A expectativa relatada pela profissional de $\mathrm{RH} 2$ quanto ao entendimento da importância do trabalho em equipe e do compartilhamento do que se sabe, é identificado no relato do entrevistado operador1, que afirma que "quando eu recebo um colega novo eu tento o máximo ensinar a ele o que aprendi, e digo para ele - você vai ter que aprender no dia a dia com a gente".

É importante destacar, que embora se fale de normas, nenhum dos entrevistados da área operacional informa sobre a existência de material escrito sobre os processos e sim, da transmissão oral. As preocupações inerentes a esta não padronização são trazidos somente pelo encarregado1, que relata o esforço da gestão para que os processos sejam anotados pelos operadores, principalmente, quando em contato com técnicos que vão à empresa para fazer algum tipo de reparo nas máquinas. Ele é enfático em dizer que sempre alerta aos demais sobre o risco de alguém ir e "levar o serviço embora com ele". Depreende-se que a maior parte do conhecimento da empresa Jazida encontra-se em um nível tácito, dependente de uma interação social que possibilite a criação, retenção, transferência e aplicação do conhecimento.

Observamos que o aprender com o outro é estimulado desde o momento da chegada, por meio de um acompanhamento constante de um profissional mais experiente. Segundo o diretor, "é o mais experiente que vai ensinar o novato". Aquilo que é trazido como uma regra da organização, que é a tarefa de ensinar aos que chegam à empresa, foi identificada tanto nas falas dos profissionais de $\mathrm{RH}$ como na do diretor, que se apresentou como algo comum na rotina dessa organização na medida em que todos os entrevistados falam de uma prática constante.

Foram recorrentes os relatos que apontavam que mesmo já tendo experiência, quando se tem uma dúvida, é natural procurar um operador mais experiente para esclarecer. Estes profissionais experientes são reconhecidos na organização como os "professores", os "jurássicos". Esta disposição e competência para ensinar se apresenta como parte do perfil do profissional da empresa Jazida. De forma recorrente, os entrevistados falam que na chegada de um novo operador, ele passa a ser ensinado, acompanhado, observado e incentivado a fazer o trabalho de forma correta.

Da mesma forma, a capacidade de ser ensinado também é um aspecto bastante valorizado. Todos os entrevistados, incluindo os gestores e os profissionais de $\mathrm{RH}$, apontam que a abertura para aprender, que muitos deles chamaram de humildade, é fundamental para o aprendizado na empresa.

O saber ouvir, o prestar atenção, o ficar ao lado observando, o praticar, o fazer de novo, o chegar com vontade, são relatados como características importantes para quem chega à empresa ou ao novo setor. Quando estas características não são observadas de imediato em alguém, há uma crença de que este profissional terá dificuldades em aprender, se tornar um operador e permanecer na empresa.

A disposição do ensinar e do aprender é fundamental para que, no dia a dia, este grupo possa experimentar novas formas de fazer, aprender novas ocupações, aprender a fazer o trabalho sem errar, com qualidade e enfrentando os novos desafios, como por exemplo, o de lidar com as máquinas automatizadas que começam a chegar ao setor e alteram a forma de trabalho já conhecida e dominada. Por mais que estes novos equipamentos venham acompanhando de um manual e de treinamento técnico dado por um especialista de fora, ainda sim, o aprender com o outro, pela transmissão do jeito de fazer é o que prevalece na empresa Jazida.

A rotina e a organização prévia se apresentaram também como fortes aliados ao processo de aprendi- 
zagem. $\mathrm{O}$ fato de se fazer algo de forma repetitiva $e$ organizado contribui para que eles aprendam, diminuindo os possíveis erros. A preparação do ambiente de trabalho antes de se iniciar, a separação de materiais e ferramentas e o cumprimento da programação, são fatos citados de forma recorrente como facilitadores diários. Cabe destacar que o erro aparece como algo comum ao processo de aprendizagem $e \mathrm{o}$ ato de aprender como algo que faz crescer.

A ideia de que os colaboradores dependem um do outro e de que ajudar faz parte do processo, é destacada por todos. O processo produtivo é visto como um conjunto de atividades que devem ser divididas e revezadas. A humildade para aprender é colocada, principalmente pelos operadores, como um requisito para aprender e permanecer na empresa, além do "querer atuar em conjunto" e o "estar disposto a colaborar", torna-se condição para o crescimento e para o reconhecimento de um bom trabalho.

A qualidade da relação que se estabelecem uns com os outros é o que garantirá o aprendizado. Para isso, a comunicação e a manutenção de bons relacionamentos se tornam fatores facilitadores do processo de aprendizagem. Para os operadores, a parte mais fácil é o ligar e o desligar das máquinas, e o difícil mesmo é "lidar com gente", porque como afirma o operador3 "pedra não fala, gente fala".

As relações no dia a dia são avaliadas pelos profissionais de $\mathrm{RH}$ como muito positivas. Os profissionais de $\mathrm{RH} 1$ e 2 relatam que os operadores mantêm um clima de harmonia, de brincadeiras entre eles e sempre que possível se reúnem para atividades de lazer fora do horário do trabalho.

É nesta cultura de interação social que ocorrem as trocas de conhecimentos, experiências e habilidades na empresa. Identificamos que a prática da socialização do conhecimento existente é o que possibilita a aprendizagem dos operadores por situações fundamentais que passam por: (1) a vontade ou o desejo da pessoa de se comunicar ativamente com seus colegas, (2) o prazer que a pessoa sente em compartilhar e ajudar os outros; e, (3) a disposição para consultar ativamente os colegas para aprender com eles.

\section{3 "Pedra tem vida própria " - 0 aprender do senso estético}

À medida que os entrevistados apresentavam seus processos de trabalho e a forma como aprendiam cada etapa, tornou explícito que, para se apropriar do conhecimento da tarefa e do entendimento do que deve ser feito com a qualidade esperada, é necessário lançar mão de recursos não só cognitivos. De forma geral, para os operadores, operar uma máquina é simples e não tem muito mistério. A tarefa mais complexa, além de lidar com gente, é trabalhar para deixar o produto bonito, limpo e preciso, já que a pedra bruta tem sua beleza própria. Questões relacionadas com o tato, a visão e as emoções emergiram nos exemplos trazidos e nos possibilitou entender que na tarefa de se tornar um operador experiente está implícito o desenvolvimento do senso estético.

Embora o diretor da empresa afirme que um trabalho de qualidade é aquele que é feito seguindo o padrão e executado com disciplina e atenção, para a equipe de produção, é o olho clínico, o que chamam de "olho do conhecimento", que assegura a entrega de um material comercialmente adequado que atenda às expectativas do cliente. Há um consenso entre eles de que este olhar não se desenvolve na escola. Além disso, acreditam que somente com a experiência adquirida no dia a dia, que será possível conhecer a história de cada material, como exemplifica o encarregado2:

Não está escrito, é olhar, não tem como você na escola aprender isso aqui. É visível não tem padrão. Cada material tem sua história e aqui não tem uma prática. Aquele material foi feito assim e conseguimos o êxito nele, os próximos que vier vai fazer da mesma forma $e$ não quer dizer que vai sair bom quanto antes. A pedra tem vida própria e você precisa conversar com ela.

O tato $e$ a visão se mostram fundamentais neste processo, desde as atividades mais simples e iniciais, como passar massa em uma pedra bruta, verificar a textura de uma chapa, até o olhar da sua estética. A textura é sinal de qualidade do produto, do que os operadores chamam de perfeição. Ao serem questionados sobre o que é um trabalho de qualidade, todos falam de um produto bonito, com brilho e liso. Embora estas características apontem para a necessidade do desenvolvimento de habilidades visuais e manuais, não foi identificado como este processo de aprendizagem se 
dá. Foi recorrente a expressão "isso é coisa que cada um desenvolve a partir do que observa", permitindo-nos entender que a estética e o conhecimento possuem uma íntima relação e que o ato de aprender tem a ver com o que cada um sente.

Ressaltamos ainda, que o conceito do belo, do feio, do limpo e do sujo extrapola a qualidade do material e chega ao ambiente de trabalho. Durante a visita à fábrica, foi possível perceber que o ambiente é bastante organizado e limpo e há uma preocupação na manutenção do espaço nestas condições. O diretor da empresa a todo instante abaixava para pegar algo no chão, levava algum objeto para o lixo, fazia questão de sinalizar caso entrássemos em algum lugar que não estava de acordo com o padrão de limpeza ou organização e a todo instante as palavras, sujo, belo, feio e limpo apareciam. Nas entrevistas, isso também foi expresso pelos profissionais operacionais, quando falam do dilema que é produzir deixando o lugar limpo e bonito.

A presença e a importância das emoções no processo de produzir é um outro aspecto que se destaca. Ao serem questionados sobre o que sentem e o que pensam enquanto produzem, foram recorrentes palavras relacionadas à alegria, satisfação, leveza, felicidade e sentimento de utilidade. De uma maneira geral, os operadores falam que para fazer um trabalho como esse, é preciso estar bem, porque caso contrário, o trabalho não sai bem feito e aí precisam fazer tudo de novo. O gostar do que se faz, para este grupo, é requisito importante para conseguir entregar o que é esperado deles.

Os dados encontrados nesta pesquisa nos permitiu estar de frente com um processo de aprendizagem que se sustenta em uma construção social, onde a colaboração, a interação, o desejo de compartilhar, a vontade de aprender e o sentimento são fontes importantes para a geração, compartilhamento e disseminação do conhecimento.

\section{Discussão e ANÁlise dos dAdos}

O fato de os operadores da empresa pesquisada aprenderem o ofício sem experiência prévia no setor ou sem uma qualificação específica, e também o fato da empresa possuir práticas que promovem o aprendizado destes profissionais, vai ao encontro dos argumentos de Gherardi $(2001,2006,2014)$ de que o aprendizado por meio da prática se configura no fluxo da experiência diária, com ou sem conhecimento específico da atividade. Os relatos apontam que a cultura da empresa é voltada para formar pessoas, que os profissionais aprendem na empresa e de que operadores mais experientes formam os que estão entrando.

O caráter social da aprendizagem é evidenciado no entendimento da importância do trabalho em equipe, do compartilhamento do que se sabe e na recepção ao colega novo, quando se ensina ao máximo do que se aprendeu, reforçando que o aprendizado se dá pela interação diária e pela colaboração. Isto é reforçado por Gherardi e Nicolini (2000) e por Gudolle, Antonello e Flach (2012), que apontam que novos membros da comunidade são socializados para suas práticas e conhecimentos distintos, ao adquirem um volume de conhecimento que eles deixam como um legado, com algumas modificações, aos seus sucessores. Dessa forma, perpetuam-se não só a comunidade, mas também o seu volume de conhecimento prático. Reforça-se, portanto, que uma prática é algo que confere identidade a um grupo que se organiza a partir dela. Logo, sua aprendizagem ocorre por meio das interações entre os atores sociais (GHERARDI; PERROTA, 2014).

O envolvimento progressivo dos recém-chegados em uma prática à medida que adquirem crescente competência é evidenciado na disposição e competência para ensinar, que se apresenta como parte integrante do perfil do profissional da empresa. Os entrevistados relatam que na chegada de um novo operador, este passa a ser ensinado, acompanhado e incentivado a produzir corretamente. Isso denota o caráter periférico apontado por Gherardi, Nicolini e Odella (1998) por meio da existência de um roteiro que o novo membro deve seguir a fim de ganhar a estima dos membros estabelecidos da comunidade, além da legítima participação, que enfatiza como o recém-chegado passa através dos vários estágios de aprendizagem, devendo, necessariamente, conectar-se com outras pessoas que exercem práticas reais (GUDOLLE; ANTONELLO; FLACH, 2012)

No que se refere à segurança como prática aprendida, embora a empresa apresente mecanismos formais de capacitação, observamos que não é exclusivamente o treinamento que assegura o aprendizado e sim, a 
prática, o cuidado, a disciplina e a atenção, tornando a segurança um processo social e não um mero "guia" do que deve ser feito. Isso evidencia a segurança como um movimento cultural em curso, ou seja, sai de um foco da segurança como um fator objetivo inerente às condições de risco para a produção social das condições de segurança sustentada por uma cultura (GHERARDI, NICOLINI; ODELLA, 1997; GHERARDI; STRATI, 2014).

Esta cultura de segurança foi muito evidenciada na empresa, que vislumbra a prática de segurança como transmitida entre eles, num processo de participação ativa e de compartilhamento de conhecimentos e experiências adquiridas. Nesse contexto, foi possível identificar a segurança como uma prática situada $e$ emergente.

A necessidade de desenvolvimento de um senso estético foi observada na empresa, onde foi possível evidenciar questões relacionadas com o tato, com a visão e com as emoções. Isso confirma o abordado por Strati (2007; 2014d) que visualiza a estética como uma forma de conhecimento humano fornecida pelos órgãos dos sentidos e pela capacidade que temos de fazer um juízo estético. Percebemos que o julgamento do que é belo na empresa é um sentimento construído individual e coletivamente, por meio das ações interativas de viver as experiências no dia a dia (STRATI, 2003, 2007, 2014a, 2014b, 2014c, 2014d), como os próprios operadores relatam. Na empresa, o senso estético não ficou restrito aos aspectos visuais e sensiveis das pedras, mas também no que se refere às questões de limpeza e organização do espaço físico (STRATI, 2007, 2014c).

Destaca-se ainda, que a questão corporal é abordada dentro do contexto de estética (GHERARDI, 2009; 2016; BERTOLINI; CAPPELLI; BRITO, 2014). Observamos na empresa diversas evidências de aspectos relacionados ao olhar e ao tato nas práticas de trabalho e aprendizagem. Ações como o passar massa em uma pedra bruta e o verificar a textura de uma chapa vão ao encontro do fazer pelo gosto (taste-making) apresentado por Gherardi (2009). Isso implica dizer que o julgamento estético como fruto do engajamento dos praticantes apontado por Gherardi (2009) e Gherardi e Strati (2014) é evidenciado na empresa, influenciando na sofisticação das práticas e mobilizando conhecimento sensível, como a habilidade corporal para perceber e gostar, além de compartilhar um vocabulário que permite a comunicação de experiências sensíveis.

As características esperadas para uma chapa de granito de qualidade são mencionadas como um produto bonito, com brilho e liso, mas não se evidenciou de que forma esse aprendizado se dá, pois os próprios entrevistados relatam que cada um desenvolve a partir do que cada um observa, logo, isso evidencia fortemente que há uma conexão estreita entre estética e conhecimento tácito, pois as pessoas adquirem o conhecimento tácito da vida organizacional pela ativação de sua percepção e do conhecimento não intelectual (STRATI, 2007; GHERARDI; STRATI, 2014).

\section{Considerações Finais}

O presente estudo buscou compreender como as práticas de trabalho possibilitam a aprendizagem dos indivíduos nos espaços de trabalho e por meio dele foi possível compreender que o processo de aprendizagem dos operadores da empresa Jazida se sustenta em uma construção social, por meio de práticas de socialização, da segurança e do senso estético, onde a colaboração, a interação, o desejo de compartilhar, a vontade de aprender, a ativação da percepção e de sentimentos são fontes importantes para a geração, a disseminação e o compartilhamento do conhecimento.

Nas práticas de socialização, foi possível identificar que a ideia de legítima participação é evidente, pois o recém-chegado passa pelos vários estágios de aprendizagem e, necessariamente se socializa com outras pessoas (LAVE; WENGER, 1991; GHERARDI, NICOLINI; ODELLA, 1998; GUDOLLE; ANTONELLO; FLACH, 2012). Portanto, desde que o conhecimento é integrado e distribuído na vida dos operadores da empresa, o aprender se torna um ato de pertencimento. Assim como a socialização, a colaboração é ressaltada de forma significativa na prática da segurança da empresa sendo transmitida entre eles, num processo de participação ativa e de compartilhamento de conhecimentos e experiências adquiridas.

Por sua vez, não se percebeu esta mesma prática da colaboração no desenvolvimento do senso estético. Apesar de os colaboradores mais antigos terem como prática ensinarem aos novatos, não identificamos uma forte relação entre a prática colaborativa e a estética. 
Mas sim, que neste aspecto, os operadores adquirem o conhecimento pela ativação de sua percepção e do conhecimento não intelectual e não exclusivamente como uma prática colaborativa.

Compreende-se que como principal limitação da pesquisa reside no fato de que as pesquisadoras não estiveram na prática, junto com os operadores, para compreender como as relações são estabelecidas. Ter baseado a compreensão em entrevistas e na observação pode limitar a compreensão do processo de aprendizagem dos operadores.

Assim, sugere-se para pesquisas futuras, a ampliação deste estudo para outros grupos profissionais de diferentes setores, tendo a prática como unidade de análise, de forma a expandir as pesquisas sobre conhecimento e aprendizagem em relação às práticas sociais, o que contribuiria para uma melhor compreensão em relação a como as pessoas aprendem umas com as outras em seu cotidiano.

Sugere-se ainda, que sejam realizados estudos empíricos sobre práticas de segurança utilizando-se da abordagem da aprendizagem baseada na prática, ampliando os estudos que tratam da segurança como uma prática revestida de significados.

\section{REFERÊNCIAS}

ANTONELLO, C. S.; GODOY, A. S. A encruzilhada da aprendizagem organizacional: uma visão multiparadigmática. RAC, Curitiba, v. 14, n. 2, p. 310-332, 2010.

BANSAL, P.; CORLEY, K. From the editors the coming of age for qualitative research. Academy of Management Journal, [S.I.] v. 54, n. 2, p. 233-237, 2011.

BECK, U. Risk society. London: Sage Publications, 1992.

BERTOLINI, R.; CAPPELLI, M.; BRITO, M. Corporeidade e estética na aprendizagem organizacional: insights emergentes. Revista de Administração Mackenzie. São Paulo, v. 15 n. 2, p. 15-37, 2014.

BISPO, M. S. Aprendizagem Organizacional Baseada no Conceito de Prática: Contribuições de Silvia Gherardi.

Revista de Administração Mackenzie, v. 14, n. 6, p. 132-161, 2013a.
BISPO, M.S. Estudos baseados em prática: conceitos, história e perspectivas. Revista Interdisciplinar de Gestão Social, [S.I.], v. 2, n. 1, p. 13-33, $2013 b$.

BISPO, M. S.; GODOY, A. S. A etnometodologia enquanto caminho teórico-metodológico para investigação da aprendizagem nas organizações. RAC, Curitiba, v. 16, n. 5, p. 684-704, 2012.

BISPO, M. de S.; MELLO, A. S. A miopia da aprendizagem coletiva nas organizações: existe uma lente para ela?

Gestão \& Planejamento, v. 12, n. 3, p. 728-745, 2012.

BOGDAN, R.; BIKLEN, S. - Características da investigação qualitativa. In: Investigação qualitativa em educação: uma introdução à teoria e aos métodos. Porto: Porto Editora, 1994. p.47- 51.

CRESWELL, J. W. W. Projeto de pesquisa: métodos qualitativo, quantitativo e misto. 2. ed. Porto Alegre: Bookman, 2010.

DAVENPORT, T.H.; DE LONG, D.; BEERS, M. Successful Knowledge Management Project. Sloan Management Review (winter): p. 43-57, 1998.

DUNDON, T.; RYAN, P. Interviewing Reluctant Respondents: Strikes, Henchmen, and Gaelic Games. Organizational

Research Methods, v.13, n.3, p. 562-581, 2010.

EASTERBY-SMITH, M.; ARAUJO, L. Aprendizagem organizacional: oportunidades e debates. In: EASTERBYSMITH, M., BURGOYNE, J.; ARAUJO, L. (Org.).

Aprendizagem organizacional e organização que aprende: desenvolvimento na teoria e na prática. São Paulo: Atlas, 2001, p. 15-34.

\section{GARFINKEL, H. Studios en Etnometodología.}

Barcelona: Anthropos, 2006.

GHERARDI, S. NICOLINI, D. The Sociological Foundations of Organizational Learning. In: DIERKES, M. et al. (Org.) Organizational learning and knowledge, Oxford: Oxford University Press, p.35-60, 2001.

GHERARDI, S. From organizational learning to practicebased knowing. Human relations, London, v. 54, n. 1, p. 131, 2001.

GHERARDI, S. Organizational Knowledge: The Texture of Workplace Learning. Oxford: Blackwell Publishing, 2006.

GHERARDI, S. Practice? It's a matter of taste!

Management Learning, [S.I.], v. 40, n. 5, p. 1-16, 2009. 
GHERARDI, S.; NICOLINI, D.; ODELLA, F. Toward a social understanding of how people learn in organizations the notion of situated curriculum. Management Learning, [S.I.], v. 29, n. 3, p. 273-297, 1998.

GHERARDI, S. NICOLINI, D. The Organizational Learning of Safety in Communities of Pratice. Journal of Management Inquiry, v. 9, n. 1, 2000.

\section{GHERARDI, S; STRATI, A. Administração e}

aprendizagem na prática. Rio de Janeiro: Elsevier, 2014.

GHERARDI, S.; NICOLINI, D.; STRATI, A. The passion for knowing. Organization. [S.I.], v. 14, n. 3, p. 315-329, 2007.

GHERARDI, S.; PERROTTA, M. Between the hand and the head: How things get done, and how in doing the ways of doing are discovered. Qualitative Research in Organizations and Management: An International Journal, v. 9, n. 2, p. 134-150, 2014.

GHERARDI, S.; RODESCHINI, G. Caring as a collective knowledgeable doing: about concern and being concerned. Management Learning, [S.I.], v.47 n. 3, p. 267-284, 2016.

GIL FLORES, J. Aproximación interpretativa al contenido de la información textual. In: Análisis de datos cualitativos: aplicaciones a la investigación educativa. Barcelona: PPU, p. 65-107, 1994.

\section{GUDOLLE, L.S.; ANTONELLO, C.S.; FLACH, L. A} aprendizagem situada, participação e legitimidade nas práticas de trabalho. Revista de Administração Mackenzie, São Paulo, v. 13, n. 1, p. 14-39, 2012.

HAGER, P. Theories of practice and their connections with learning: a continuum of more and less inclusive accounts. In: HAGER, P.; LEE, A.; REICH, A. (Ed.). Learning practice and change: practice-theory perspectives on professional learning. Dordrecht: Springer International. p. 17-32, 2012.

KING, N. The Qualitative Research Interview. In: CASSELL, C. \& SYMON, G. (Eds.) Qualitative Methods in Organizational Research. London/New Delhi: Sage Publications, 1997.
KUNIYOSHI, M. S. Institucionalização da gestão do conhecimento: um estudo das práticas gerenciais e suas contribuições para o poder de competição das empresas do setor elétrico-eletrônico. 210f. Tese (Doutorado em Administração) - Universidade de São Paulo, 2008.

NICOLINI, D., GHERARDI, S., YANOW, D. Introduction: towards a practice-based view of knowing and learning in organisations. In: Nicolini, D., Gherardi, S., Yanow, D. (Eds.), Knowing in Organisations: A Practice-Based Approach, M.E. Sharpe, London, p.3-31, 2003.

NONAKA, I.; TAKEUCHI, T. Criação de Conhecimento na Empresa. Rio de Janeiro: Campus, 1997.

PRANGE, C. Aprendizagem organizacional: desesperadamente em busca de teorias? In: EASTERBYSMITH, M., BURGOYNE, J.; ARAUJO, L. (orgs.). Aprendizagem organizacional e organização que aprende: desenvolvimento na teoria e na prática. São Paulo: Atlas, 2001, p. 41-63.

RYAN, G. W; BERNARD, R. Techniques to Identify Themes. Field Methods, (15)1, 85-109, 2003.

ROSEN, M. Coming to terms with the field: understanding and doing organizational ethnography. Journal of Management Studies, (28)1, p. 1-24, 1991.

SENGE, M. P. A Quinta Disciplina: Arte e prática da organização que aprende. Rio de Janeiro: Best Seller, 2010.

RECKWITZ, A. Toward a theory of social practices a development in culturalist theorizing. European Journal of Social Theory, [S.I.], v. 5, n. 2, p. 243-263, 2002.

STEWART, T. Your Company's Most Valuable Asset: Intellectual Capital. [S.I.], Fortune, 1994.

STRATI, A. Knowing in practice: aesthetic understanding and tacit knowledge. In: NICOLINI, D.; GHERARDI, S.; YANOW, D. (eds.). Knowing in organizations: a practice-based approach. New York: M.E. Sharpe.p. 5375, 2003.

Organização e estética. Rio de Janeiro: Editora FGV, 2007. 320 p.

STRATI; A. Saber na prática: compreensão estética e conhecimento tácito. In: GHERARDI, S.; STRATI, A. Administração e aprendizagem na prática. Rio de Janeiro: Elsevier, 2014a, p. 19-42. 
STRATI; A. Conhecimento sensível e aprendizagem baseada na prática. In: GHERARDI, S.; STRATI, A.

Administração e aprendizagem na prática.

Rio de Janeiro: Elsevier, 2014b, p. 61-82.

STRATI; A. Estética no estudo da vida organizacional. In: GHERARDI, S.; STRATI, A. Administração e aprendizagem na prática. Rio de Janeiro: Elsevier, 2014c, p.103-116.
STRATI; A. "Você faz coisas belas? ": estética e arte em métodos qualitativos de estudos organizacionais. In: GHERARDI, S.; STRATI, A. Administração e aprendizagem na prática. Rio de Janeiro: Elsevier. 2014d, p.171-196.

TURNER, B. A.; PIDGEON, N. Man-made disasters. Newton, MA: Butterworth-Heinemann, 1997. 